\title{
Seasonal changes in glenohumeral joint isokinetic strength in professional rugby league players
}

\author{
Matthew R. Haines ${ }^{\text {a, }}{ }^{*}$, Michael Fish ${ }^{\text {a }}$, and David O'Sullivan ${ }^{\text {b }}$
}

a Division of Sport, Exercise, and Nutrition Sciences; University of Huddersfield; Huddersfield; United Kingdom

b The ProSport Academy Ltd; Huddersfield; United Kingdom

* Corresponding author:

Dr Matthew Haines

University of Huddersfield

School of Human and Health Sciences

Queensgate campus

Huddersfield, HD1 3DH, United Kingdom

Email address: m.haines@hud.ac.uk 


\section{$\underline{\text { Abstract }}$}

Objective: To assess glenohumeral joint (GHJ) rotation strength across a rugby league season, since strength of rotator cuff musculature may protect against contact injuries to the shoulder.

Design: A prospective cohort study was used to compare GHJ rotation pre-, in-, and post-season.

Setting: Laboratory.

Participants: Twenty-nine players from a professional European Super League club.

Main Outcome Measures: Isokinetic dynamometry for concentric and eccentric muscle actions for shoulder internal and external rotation at $240 \%$ s. Peak torque, traditional strength ratios, and dynamic control ratios were compared.

Results: There were no significant differences between peak torque strength parameters at any time point. Similarly, differences in strength ratios failed to reach statistical significance across the season. Ipsilateral strength ratios were indicative of selective strengthening of internal rotators for concentric and eccentric muscle actions.

Conclusions: The findings suggest that rugby league players are no more likely to sustain a shoulder injury in the latter stages of the season as a result of decreased GHJ rotation strength. Players were able to maintain strength across the season which is valuable to practitioners developing conditioning programmes to optimise performance and minimise the risk of injury. This may afford protection, particularly during forced external rotation following physical contact.

Keywords: Glenohumeral joint; rotator cuff; isokinetic strength; rugby league 


\section{INTRODUCTION}

Rugby league is an international sport played at amateur, semi-professional, and professional levels. It is a collision sport characterised by frequent physical contacts and high impact forces during offensive and defensive play. Consequently, musculoskeletal injuries are common. A recent study including all European Super League (ESL) teams reported an overall injury incidence of 57 injuries per 1000 game hours over three seasons ${ }^{13}$, similar to a previous pooled data analysis of professional players (40.3 injuries per 1000 hours). ${ }^{20}$ However, research in Australian semi-professional players reported much higher injury rates. ${ }^{15}$ Despite this variability, which could be explained by differing definitions of injury, it is clear that injury results in significant time loss from playing and training in rugby league.

Shoulder injuries are common (6-28\% of all injuries) $)^{15232635}$ and often severe. ${ }^{213}$ For example, in a recent epidemiological study the mean number of days missed for acromioclavicular joint injury (22 days), shoulder dislocation (88 days), and glenohumeral joint (GHJ) sprain (51 days)

were among the most severe injuries. ${ }^{13}$ It has also been suggested that the severity of shoulder injuries has increased as gameplay has become more aggressive and intense as the game has changed from being largely an amateur sport to one that is played at a professional level. ${ }^{7}$ These are timely considerations in the ESL as recent rule changes have been implemented to reduce the number of interchanges and the duration of stoppages in games with the intention of improving entertainment for fans, both of which could increase player fatigue. Fatigue-induced decrements in tackling technique are evident in rugby ${ }^{17}{ }^{38}$, thus an unintended consequence might be an increase in the incidence of injury. The mechanisms of traumatic shoulder injury have been outlined previously. ${ }^{6}{ }^{24}$ Typically, tackle activities result in impact directed to the anterior-superior surface of the shoulder and arm resulting in forced external rotation and horizontal abduction of the humerus with subsequent leveraging forces over the GHJ. This predominantly causes GHJ dislocation with Bankart, reverse Bankart, and superior labrum 
anterior-posterior lesions. Injury may also occur when the ball carrier enters a tackle with an adducted arm placed on the front-side of contact as a shield-mechanism, exposing the joint to excessive collision force, resulting in acromioclavicular joint dislocation and scapula fractures. 624

Considering the inherent design of the GHJ, which permits mobility at the expense of osseous stability, active muscle stabilisation and muscle strength balance are essential to maintain stability and optimal positioning of the humeral head. ${ }^{4}$ As such, increasing strength of the rotator cuff and scapular musculature could protect rugby league players against contact injuries. Specifically, the ability of the subscapularis muscle to eccentrically avoid forced external rotation could reduce injury risk. Gabbett et al. ${ }^{19}$ used a regression model to predict that increased upper-body strength and power may reduce the risk of contact injury in professional players. Furthermore, McDonough \& Funk ${ }^{31}$ used GHJ isokinetic strength and range of movement to predict injury in a small group of professional rugby league players. Although the isokinetic strength parameters did not reach statistical significance, a moderate effect size (Cohen's $d=0.83$ ) was reported for eccentric internal rotation strength suggesting this may be clinically important. However, enhanced muscle strength should not be considered in isolation because the existence of a reciprocal muscle strength imbalance across the GHJ could contribute to joint instability. Haines ${ }^{21}$ observed selective muscular development of the internal rotators without concomitant external rotation strength in professional players. Although speculative, this could increase the risk of injury in rugby league players as evidenced in several other sports. ${ }^{12}$

Incidence of injury across a season is also important because research with rugby league players has demonstrated that injuries are more frequently sustained in the latter stages of the season. ${ }^{1} 151626$ Although other research contradicts this finding, ${ }^{13}$ it is reasonable to assume that local muscular fatigue or seasonal accumulative microtrauma, or both, may contribute to 
injuries in rugby league. ${ }^{16}$ Sensory motor system deficits following repeated tackling and fatigue have been shown to decrease accuracy of joint position sense in players and may also contribute to micro-instability of the GHJ and subsequent injuries later in the season. ${ }^{25} 34$ Significant decreases in lean muscle mass ${ }^{19} 22$ and bone mass ${ }^{19}$ have been observed for professional players across a season. Such changes could deleteriously alter GHJ strength as the playing season progresses resulting in an associated diminishing probability of remaining injury free. This conceivable risk factor for shoulder injury in rugby league players has not been explored. Therefore, our aim was to examine GHJ isokinetic strength for professional rugby league players across a season using isokinetic dynamometry. This included gaining a better understanding of ipsilateral strength ratios, including dynamic control ratios (DCR's) which compare opposite muscle actions of antagonistic muscle groups. This is proposed as a potential moderator for the risk of shoulder injury following forced external rotation. 


\section{MATERIALS AND METHODS}

\section{$\underline{\text { Experimental design }}$}

With institutional ethics approval and permission from an ESL club, a prospective cohort study was used to compare GHJ strength across a season. This was assessed pre-, in-, and post-season using isokinetic dynamometry. Players first attended the laboratory for testing during the latter stages of pre-season (January) before their first competitive league game. In-season testing (June) was undertaken after approximately half of the seasons competitive fixtures and was recorded mid-week to minimise the influence of match related fatigue. Post-season testing (October) was carried out after the final competitive fixture. Players attended the laboratory at the same time of day and were instructed to consume their normal diet and to refrain from intense exercise prior to each testing session. Blinding of assessors who measured outcome measures was not possible.

\section{$\underline{\text { Sample }}$}

Twenty-nine professional players provided written informed consent to undertake testing (mean \pm SD: stature, $1.83 \mathrm{~m} \pm 0.05 \mathrm{~m}$; mass, $96.9 \pm 12.2 \mathrm{~kg}$; age, $26.8 \pm 4.1$ years). There were no players under the age of 18 years in this study (range 18 to 32 years). The players included were representative of the team's first-grade squad and therefore included both forwards (props, hookers, second rowers, and loose forwards) and backs (half-backs, centers, wingers, and full-backs) with varied playing experience. Players were excluded if they had current shoulder pathology or if they had received neck or shoulder surgery within the previous 16 weeks.

\section{$\underline{\text { Isokinetic dynamometry }}$}

Isokinetic dynamometry was used to assess GHJ rotation using a Cybex HUMAC (HUMan Assessment Computer) NORM Testing and Rehabilitation System with HUMAC2009 
software version 9.8.4 (CSMI, Stoughton, MA, USA). The dynamometer calibration was checked before each testing session, and gravity correction was applied to torque data by weighing the limb in a relaxed position with the arm at anatomical zero (see below for definition). The fastest manufacturer cushion setting of 5 was used to decelerate the dynamometer arm to $0 \% \mathrm{~s}^{-1}$ at the ends of the range of movement (ROM).

A modified base position was used with the player standing. With the dynamometer tilted at $30^{\circ}$ from the transverse plane, the GHJ was placed in $30^{\circ}$ of abduction and $30^{\circ}$ of forward flexion into the scapular plane (scaption). The olecranon was aligned with the dynamometer's mechanical axis of rotation with the dynamometer height adjusted to ensure that the shoulder was in a neutral position (i.e. not elevated or depressed). Although this position does not accurately replicate the position of tackling, functional activity rarely occurs in the frontal or sagittal plane but rather in a mid-position of flexion and abduction so this protocol was considered a compromise between these two positions to mimic actions during rugby league game play. This protocol also minimizes the risk of suprahumeral impingement and is deemed safe for most pathologies and postoperatively. ${ }^{11}$ Relative technical error of measurement values ranging from $3.2 \%$ to $4.9 \%$ (dependant on dynamometer speed) have been recorded for shoulder rotation in the scapular plane test position in our laboratory, which is in line with other research that has shown that this can be measured reliably. ${ }^{30}$

Concentric and eccentric muscle actions for shoulder internal and external rotation were evaluated at $240^{\circ} / \mathrm{s}^{-1}$. Within manufacturer recommended ROM limits, of $80^{\circ}$ internal rotation and $60^{\circ}$ external rotation relative to anatomical zero (defined as $0^{\circ}$ with the forearm placed in the sagittal plane), players self-selected a "comfortable" ROM. To familiarize, players performed 3 submaximal repetitions for each action, followed by a warm-up set at $120^{\circ} / \mathrm{s}^{-1}$. Players then performed 4 maximal repetitions for each action in a standardised order, before repeating on the contralateral limb. Verbal encouragement and visual feedback in the form of 
peak torque bars for each repetition were used throughout to encourage maximal effort for all actions. It was not possible to secure players with pelvic and diagonal straps for trunk stabilisation because of the standing position, although players were encouraged to maintain a strict technique only moving at the shoulder. Torque versus position curves were inspected for each repetition, to check for spurious data, with peak torque recorded for each action.

Traditional strength ratios were calculated as concentric external rotator strength to concentric internal rotator strength. Based on the work of others, ${ }^{31}$ DCR's were calculated as eccentric internal rotator strength to concentric external rotator strength.

\section{$\underline{\text { Statistical analyses }}$}

Analyses were carried out using IBM SPSS Statistics version 24 (IBM, Armonk, USA) with the criterion for statistical significance set at $\mathrm{p}<0.05$. Six participants had partially missing data. Therefore, prior to analysing data, missing values were imputed using expectation maximisation to reduce bias and preserve all cases by replacing missing data with an estimated value. There was no evidence that data was not missing completely at random, and imputation did not introduce bias because values (mean \pm standard deviation) did not substantively change following imputation. Following this, assumptions of tests were satisfied before a one-way, repeated measures analysis of variance was conducted for all outcome measures, applying the Greenhouse-Geisser correction when the sphericity assumption was violated. Familywise error rate was controlled using Bonferroni corrections. Effect sizes were quantified using the partial eta squared $\left(\eta^{2}\right)$ statistic to examine the magnitude of differences between time points, with values of $0.1-0.29,0.3-0.49$, and $\geq 0.5$ considered to be small, medium, and large effects, respectively. Separate independent samples t-tests were used to determine differences between right and left GHJ strength values. 


\section{RESULTS}

Twenty-three participants (79\% of players) provided data at all three time points. Six players had partially missing data due to unavailability at the time of testing. Repeated measures analysis of variance revealed no significant differences and small effect sizes for all internal rotation (figure 1) and external rotation (figure 2) values across the season for both absolute values and when presented as a ratio standard adjusted relative to body mass (table 1). Independent samples $t$-tests also revealed there were no significant differences between right and left GHJ strength values at any time point. Similarly, traditional ratio and DCR strength parameters failed to reach statistical significance at all time points and between right and left GHJ values (table 2). There was a trend for players to reduce mass across a season, although this was not statistically significant.

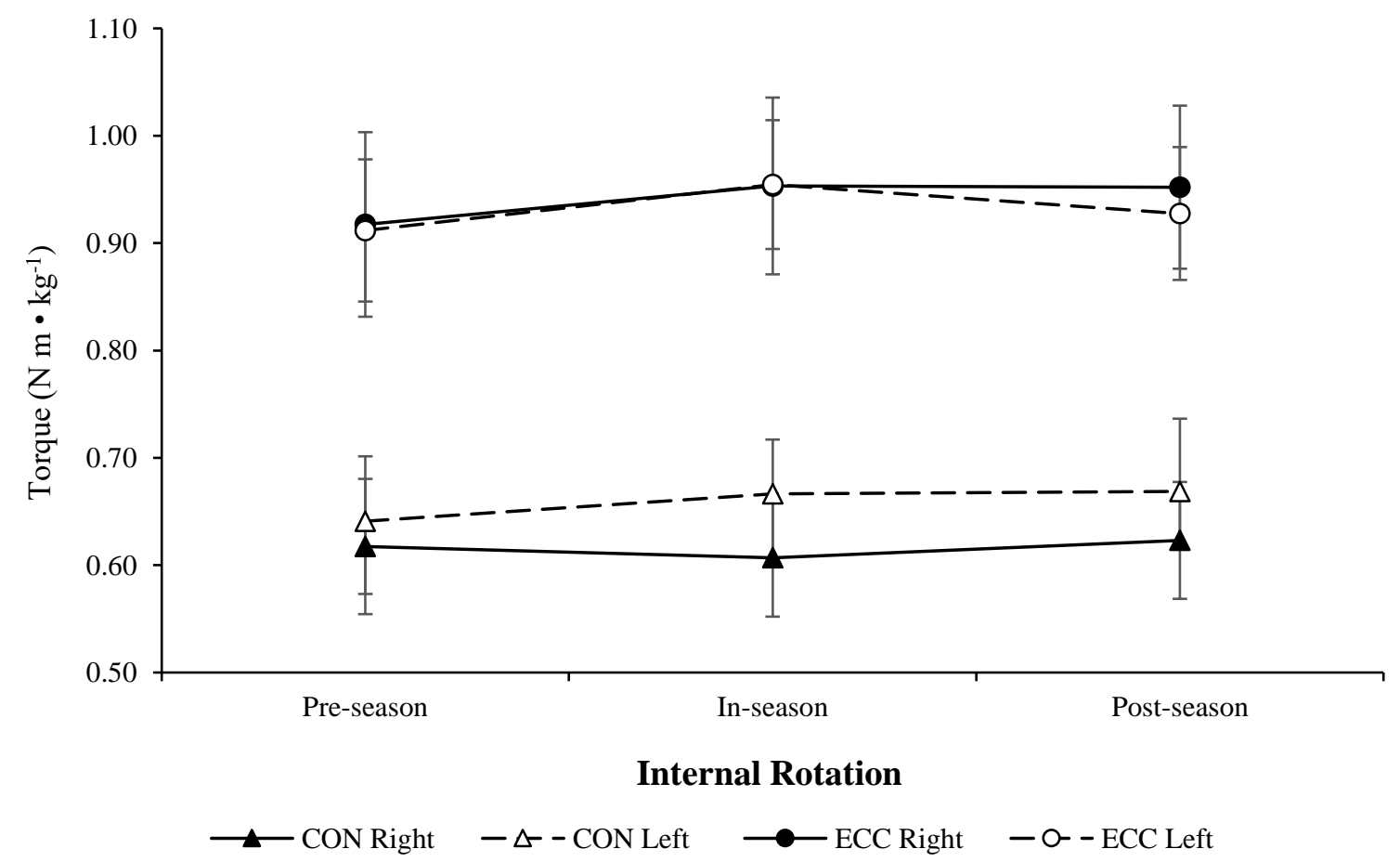

Figure 1. Glenohumeral joint internal rotation peak torque values relative to body mass across a season. Abbreviations: $\mathrm{CON}=$ concentric; $\mathrm{ECC}=$ eccentric. Note: Data are presented as mean $\pm 95 \%$ confidence intervals 


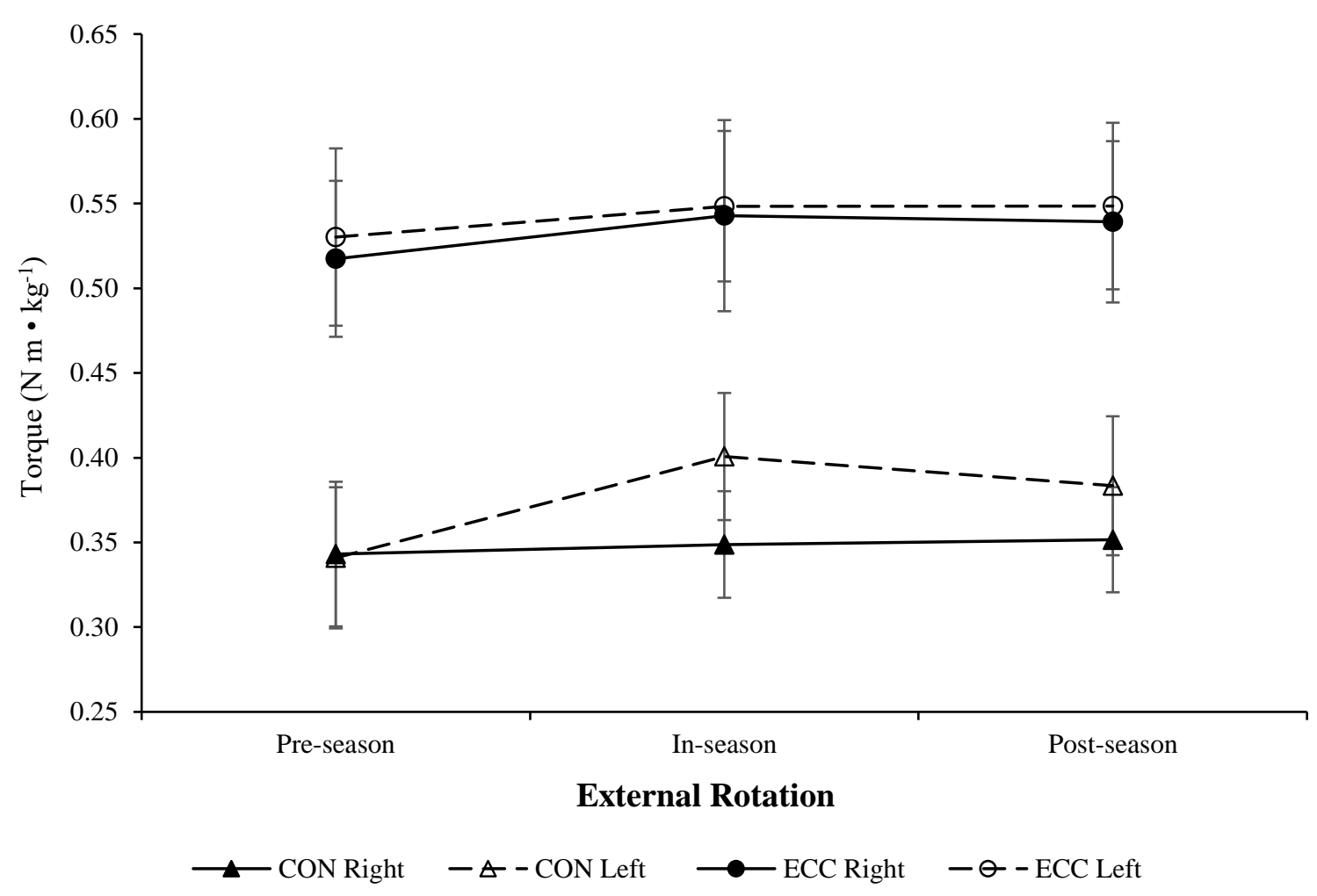

Figure 2. Glenohumeral joint external rotation peak torque values relative to body mass across a season. Abbreviations: $\mathrm{CON}=$ concentric; $\mathrm{ECC}=$ eccentric. Note: Data are presented as mean $\pm 95 \%$ confidence intervals

Table 1. Isokinetic dynamometry peak torque for GHJ rotation strength recorded pre-, in-, and postseason. Values are presented as absolute measures and as a ratio standard adjusted for body mass. Values are mean \pm standard deviation.

\begin{tabular}{|c|c|c|c|c|c|c|c|c|c|}
\hline & & \multicolumn{2}{|c|}{ Pre-season } & \multicolumn{2}{|c|}{ In-season } & \multicolumn{2}{|c|}{ Post-season } & \multirow[t]{2}{*}{$\mathbf{P}$} & \multirow[t]{2}{*}{$\eta^{2}$} \\
\hline & & $\mathrm{Nm}$ & $\mathrm{N} \mathrm{m} \cdot \mathrm{kg}^{-1}$ & $\mathrm{Nm}$ & $\mathrm{N} \mathrm{m} \cdot \mathrm{kg}^{-1}$ & $\mathrm{~N} \mathrm{~m}$ & $\mathrm{~N} \mathrm{~m} \cdot \mathrm{kg}^{-1}$ & & \\
\hline \multicolumn{10}{|c|}{ Internal rotation } \\
\hline & $\mathbf{R}$ & $60 \pm 19.3$ & $0.62 \pm 0.17$ & $58.8 \pm 17.3$ & $0.61 \pm 0.15$ & $59.9 \pm 16.5$ & $0.62 \pm 0.15$ & 0.88 & 0.01 \\
\hline \multirow[t]{3}{*}{$\mathrm{CON}$} & $\mathbf{L}$ & $62.3 \pm 20.7$ & $0.64 \pm 0.19$ & $64.1 \pm 15.8$ & $0.67 \pm 0.17$ & $64 \pm 13.5$ & $0.67 \pm 0.14$ & 0.70 & 0.01 \\
\hline & $\Delta$ & $3.8 \%$ & $3.7 \%$ & $9 \%$ & $8.9 \%$ & $6.7 \%$ & $6.8 \%$ & - & - \\
\hline & $\mathbf{R}$ & $88.3 \pm 22.2$ & $0.92 \pm 0.24$ & $91.1 \pm 19.2$ & $0.95 \pm 0.23$ & $91.1 \pm 20.3$ & $0.95 \pm 0.21$ & 0.60 & 0.02 \\
\hline \multirow[t]{2}{*}{ ECC } & $\mathbf{L}$ & $88 \pm 18.3$ & $0.91 \pm 0.18$ & $91.4 \pm 13.9$ & $0.95 \pm 0.16$ & $88.5 \pm 14.6$ & $0.93 \pm 0.17$ & 0.37 & 0.03 \\
\hline & $\Delta$ & $0.4 \%$ & $0.6 \%$ & $0.4 \%$ & $0.1 \%$ & $2.9 \%$ & $2.6 \%$ & - & - \\
\hline \multicolumn{10}{|c|}{ External rotation } \\
\hline & $\mathbf{R}$ & $33.5 \pm 12.7$ & $0.34 \pm 0.12$ & $33.7 \pm 9.4$ & $0.35 \pm 0.09$ & $33.9 \pm 9.4$ & 0.350 .09 & 0.89 & 0 \\
\hline \multirow[t]{3}{*}{$\mathrm{CON}$} & $\mathbf{L}$ & $34.7 \pm 8.9$ & $0.34 \pm 0.11$ & $38.2 \pm 8.4$ & $0.40 \pm 0.10$ & $36.4 \pm 10.1$ & $0.38 \pm 0.11$ & 0.10 & 0.08 \\
\hline & $\Delta$ & $1.4 \%$ & $0.6 \%$ & $13.1 \%$ & $13 \%$ & $7.5 \%$ & $8.3 \%$ & - & - \\
\hline & $\mathbf{R}$ & $50 \pm 12.5$ & $0.52 \pm 0.13$ & $52.6 \pm 13$ & $0.54 \pm 0.15$ & $51.6 \pm 12.2$ & $0.54 \pm 0.13$ & 0.30 & 0.04 \\
\hline \multirow{2}{*}{ ECC } & $\mathbf{L}$ & $51.3 \pm 14.7$ & $0.53 \pm 0.14$ & $52.5 \pm 10.6$ & $0.55 \pm 0.12$ & $52.5 \pm 13.1$ & $0.55 \pm 0.14$ & 0.75 & 0.01 \\
\hline & $\Delta$ & $2.6 \%$ & $2.4 \%$ & $0.3 \%$ & $1 \%$ & $1.8 \%$ & $1.7 \%$ & - & - \\
\hline
\end{tabular}

$\mathrm{CON}=$ concentric $; \mathrm{ECC}=$ eccentric $; \mathrm{GHJ}=$ glenohumeral joint $\mathrm{L}=$ left $\mathrm{R}=$ right $\Delta=$ difference between right and left GHJ. 
Table 2. Isokinetic dynamometry GHJ rotation strength ratios recorded pre-, in-, and post-season. Values are mean \pm standard deviation.

\begin{tabular}{lccccc}
\hline & Pre-season & In-season & Post-season & P & $\eta^{2}$ \\
\hline Traditional & & & & & \\
$\quad$ Right & $0.59 \pm 0.26$ & $0.59 \pm 0.14$ & $0.58 \pm 0.15$ & 0.4 & 0.04 \\
$\quad$ Left & $0.54 \pm 0.16$ & $0.64 \pm 0.23$ & $0.58 \pm 0.16$ & 0.6 & 0.12 \\
DCR & & & & & \\
$\quad$ Right & $2.56 \pm 0.71$ & $2.87 \pm 1.11$ & $2.63 \pm 0.72$ & 0.8 & 0.08 \\
$\quad$ Left & $2.87 \pm 1.11$ & $2.5 \pm 0.54$ & $2.61 \pm 0.83$ & 0.8 & 0.01 \\
\hline
\end{tabular}

$\mathrm{DCR}=$ Dynamic control ratio; $\mathrm{GHJ}=$ glenohumeral joint.

Traditional ratio measured as internal rotation concentric:external rotation concentric; DCR measured as internal rotation eccentric:external rotation concentric. 


\section{CONCLUSIONS}

The premise for investigating GHJ function in rugby league players was predicated on the assumption that sub-optimal strength of rotator cuff skeletal muscles, might increase the probability of sustaining a shoulder injury. To the authors' knowledge this is the first study to empirically compare GHJ strength parameters in a professional team across a season. Furthermore, DCR's have been proposed to screen for forced external rotation shoulder injuries in rugby league but have only been reported in a single study.

The main finding was that isokinetic dynamometry did not show significant differences in strength parameters across the season for any of the muscle actions, irrespective of whether the values were absolute measures or adjusted for body mass. Research suggests the incidence of injury increases as the season progresses,${ }^{15}$ but the implication of the null finding in the current study is that players are no more likely to sustain a shoulder injury in the latter stages of the season as a result of reduced muscle strength. This is of practical value to practitioners who design selective conditioning programmes to improve the stability and strength of scapular muscles to better tolerate the repeated physical confrontations inherent in the game. If players can maintain strength throughout the season, especially for eccentric muscle actions (forced external rotation), they may be able to withstand rapid limb acceleration and leveraging forces across the GHJ reducing the probability of injury. This may also enhance defensive play via an improved ability to tackle and hold up offensive players to prevent off-loading of the ball during a tackle. However, these findings do not rule out sensory motor changes which may increase the risk of injury and could occur across the season. Also, it is not known if the protective effect of maintaining strength across a season differs for acute injuries involving direct contact (e.g. when tackling or being tackled) and atraumatic injuries of gradual onset. Both are important in rugby league, although most injuries to the shoulder are caused following direct contact. $^{31}$ 
We propose that conditioning of the players throughout the season may have contributed to maintenance of GHJ strength. Dependant on game schedules, players followed a daily movement-based pre-rehabilitation program consisting of 3-dimensional, whole kinetic chain movements (e.g. holding a press-up position whilst performing hip, knee, and ankle joint movements). Before training, players also completed movements to lengthen the musculotendinous tissues around the pectoral region integrated with hip joint movements. Using functional postures and activities combined with shoulder exercise, in addition to simulated contact in a controlled environment whilst fatigued, can help to improve joint proprioception. ${ }^{32}$ Throughout the season, players performed a strength training programme with exercises designed to increase strength and power of shoulder and scapular muscles to better tolerate repeated physical confrontations (e.g. bench press, shoulder press, dumbbell row variations). Players also undertook wrestle/contact sessions twice per week during pre-season and once per week during the in-season period. Players did not perform isolated rotator cuff strengthening exercises since exercises that recruit individual muscles are not necessarily optimal because muscle co-contraction and coordination are important for good scapula mechanics. $^{36}$

Strength ratios remained consistent across the season. A ratio of the concentric external rotator strength to the concentric internal rotator strength has traditionally been used to assess GHJ function in sport, ${ }^{29} 38$ with a ratio of $\sim 0.66$ considered normal in the absence of pathology. ${ }^{528}$ Using a traditional strength ratio in rugby, Edouard et al. ${ }^{8}$ reported no rotator muscle imbalance in national and regional level players. This contrasts with data from an ESL team where mean values of 0.47 were reported. ${ }^{21}$ In the current study, traditional ratios were higher than this, yet lower than normal with a mean ratio of 0.58 . This is indicative of selective muscular development of the internal rotators including subscapularis, pectoralis major, and latissimus dorsi. A compromise resulting from increased internal rotation strength might be a decrease of active stabilisation through strength imbalance, which could increase the risk of GHJ injury. ${ }^{40}$ 
This should be interpreted with caution because the relevance of muscle imbalance in relation to traumatic shoulder injury in rugby, predominantly following impact during tackling, is not as clear as for overuse shoulder injuries in overhead sports such as tennis and badminton. Thus, ratios lower than normal should not be automatically considered as pathogenic. ${ }^{4}$ Yet, modern professional rugby league players complete considerable strength training and can develop imbalances typical of weightlifters ${ }^{26}$ so comprehensive isokinetic testing of the shoulder remains a useful screening tool. From an applied perspective a decision should be made whether to maintain an imbalance, which could optimise performance and potentially reduce risk of injury by increasing tolerance of impact forces, or to try and obtain muscular rebalance which could prevent overuse injuries but negatively affect performance.

A more functional approach for considering GHJ function is to use DCR's. An appropriate DCR for rugby league has been hypothesised as eccentric internal rotation to concentric external rotation, based on the shoulders ability to eccentrically avoid forced external rotation. McDonough \& Funk ${ }^{31}$ found DCR values in the region of 1.7 to 1.9. Using the same DCR, values in the current study were higher with a mean value of 2.7 which is indicative of increased eccentric internal rotation strength which could protect the GHJ during gameplay. Several factors could explain the disparity in these findings. In the present study, participants were professional players at an ESL club, whereas McDonough \& Funk ${ }^{31}$ used both professional and semi-professional players. Differences in playing standard and associated player conditioning could account for increased eccentric muscle strength, explained by the greater amount of time that professional players can dedicate to strength and conditioning compared to their semi-professional counterparts. ${ }^{21}$ Furthermore, a modified standing position was used in the current study with the arm placed in $30^{\circ}$ of abduction and $30^{\circ}$ of forward flexion into the scapular plane, whereas McDonough \& Funk ${ }^{31}$ used a seated position with the arm at $90^{\circ}$. Evidence suggests movement in the scapular plane is more reliable, ${ }^{9}$ but it is conceivable that the standing position might lead to an overestimation of peak torque values if a strict technique 
is not maintained. Positioning in the scapular plane also permits an enhanced length-tension relationship of the rotator cuff muscles which could alter strength ratios. Testing was also performed at a faster speed in the current study, which may favour eccentric actions, although GHJ rotation might be one of few ipsilateral strength ratios that remains consistent across the rotation speed spectrum. ${ }^{10}$ Further research is required to explore the use of DCR's in anticipating risk of injury in rugby league players.

Several limitations should be considered alongside the findings of this study. The reliability of isokinetic dynamometry is generally higher at slower speeds, ${ }^{33}$ and although $240^{\circ} / \mathrm{s}$ represents a faster sport specific speed compared to previous studies, the controlled and constant speed of movement inherent in isokinetic dynamometry is an imperfect surrogate for the rapid accelerations that occur during rugby league gameplay. Also, it has been suggested that rate of force development could be a better prognostic indicator of shoulder function compared to peak torque in isolation, since changes in time to peak torque and acceleration have been associated with shoulder impingement syndrome. ${ }^{3}$ Again, the range of motion where rotator cuff muscles are functioning as a decelerator might be an important consideration in shoulder strength assessment. ${ }^{37}$ Although this is likely to be the end of ROM in the overhead athlete, it is not clear when eccentric internal rotators are most active during contact during rugby league. A further limitation relates to the generalisability of the results. Although a representative sample of player positions were used in the current study (i.e. a full player roster), differences in strength were examined across one season for a single club, thus the confined cohort may not be representative of the wider competition. It is also conceivable that in-season measures recorded mid-week were not representative of strength values on game days, or indeed throughout a game, concealing short-term fatigue which may be more pronounced as the season progresses. Player position, limb dominance, preferred tackling arm, and previous injury are covariables that were not considered. 
In summary, the players in this cohort study were able to maintain GHJ strength across a rugby league season. There were no differences in any of the strength parameters at any time point suggesting that players are no more likely to sustain a shoulder injury later in the season as a result of decreased rotator cuff strength. Ipsilateral strength ratios were indicative of selective development of internal rotators for both concentric and eccentric muscle actions. This may provide some protection against forced external rotation with implications for practitioners to design practices that minimise risk of injury while optimising performance. Although optimal strength ratios are likely important to promote control of scapular humeral motions in rugby league players, inferences regarding injury risk remain speculative. Future research should compare isokinetic data alongside injury surveillance, and monitoring of workload and match exposure throughout the season. Finally, there is a need to evaluate the magnitude and causes of inter-individual differences between players. Focussing only on average responses obfuscates the inherent variability in these measures, which could be important when screening for shoulder injury in rugby league. 


\section{REFERENCES}

1. Alexander D, Kennedy M, Kennedy J. Rugby league football injuries over two competition seasons. Med J Aust 1980;2:334-5.

2. Bathgate A, Best JP, Craig, et al. A prospective study of injuries to elite Australian rugby union players. Br J Sports Med 2002;36:265-9.

3. Camargo PR, Avila MA, Asso NA, et al. Muscle performance during isokinetic concentric and eccentric abduction in subjects with sub-acromial impingement syndrome. Eur J App Physiol 2007;15:287-93.

4. Codine P, Bernard PL, Pocholle M, et al. Influence of sports discipline on shoulder rotator cuff balance. Med Sci Sport Exerc 1997; 29:1400-05.

5. Cools AM, Vanderstukken F, Vereecken F, et al. Eccentric and isometric shoulder rotator cuff strength testing using a hand-held dynamometer: Reference values for overhead athletes. Knee Surg, Sports Traum, Arthr 2016;24:2828-47.

6. Crichton J, Jones DR, Funk L. Mechanisms of traumatic injury in elite rugby players. Br J Sports Med 2012;46:538-42.

7. De Beer J, Bhatia DN. Shoulder injuries in rugby players. Int J Shoulder Surg 2009;3:1-3.

8. Edouard P, Frize N, Calmels P, et al. Influence of rugby practice on shoulder internal and external rotators strength. Int J Sports Med 2009;30:863-7.

9. Edouard P, Samozino P, Julia M, et al. Reliability of isokinetic assessment of shoulder-rotator strength: a systematic review of the effect of position. J Sports Rehab 2011;20:367-83.

10. Ellenbecker TS, Davies, GJ. The application of isokinetics in testing and rehabilitation of the shoulder complex. J Ath Training 2000;35:338-50.

11. Ellenbecker TS, Derscheid GL. Rehabilitation of overuse injuries of the shoulder. Clin Sports Med 1989;8:583-604.

12. Ellenbecker TS, Roetert EP. Testing isokinetic muscular fatigue of shoulder internal and external rotation in elite junior tennis players. J Orth Sports Phs Ther 1999; 29:275-281.

13. Fitzpatrick AC, Naylor, AS, Myler P, et al. A three-year epidemiological prospective cohort study of rugby league match injuries from the European Super League. J Sci Med Sport 2017;21:160-65.

14. Gabbett TJ, Ullah S, Finch CF. Identifying risk factors for contact injury in professional rugby league players - Application of a frailty model for recurrent injury. Med Sci Sports Exerc 2012;15:496-504.

15. Gabbett TJ. Incidence of injury in semi-professional rugby league players. Br J Sports Med 2003;37:36-44.

16. Gabbett TJ. Incidence, site, and nature of injuries in amateur rugby league over three consecutive seasons. Br J Sports Med 2000;34:98-103.

17. Gabbett TJ. Influence of fatigue on talking in rugby league players. $J$ Strength Cond Res 2016;22:625-632.

18. Gabbett TJ. Influence of fatigue on talking in rugby league players: Role of muscular strength, endurance, and aerobic qualities. PLoS ONE 2016;11:e0163161

19. Georgeson EC, Weeks BK, McLellan C, et al. Seasonal change in bone, muscle and fat in professional rugby league players and its relationship to injury: a cohort study. BMJ Open 2012;2: e001400. doi:10.1136/bmjopen-2012-001400

20. Gissane C, Jennings D, Kerr K, et al. Injury rates in rugby league football: impact of change in playing season. The Am J Sports Med 2003;31: 954-58.

21. Haines M. Differences in glenohumeral joint rotation and peak power output between Super League and Championship rugby league players. J Strength Cond Res 2018;32:1685-1691. 
22. Harley J, Hind K, O’Hara J. Three-Compartment Body Composition Changes in elite Rugby League Players During a Super League Season, Measured by Dual-Energy X-ray Absorptiometry. J Strength Cond Res 2011;25:1024-1029.

23. Headey J, Brooks JH, Kemp SP. The epidemiology of shoulder injuries in English professional rugby union. Am J Sports Med 2007;35:1537-43.

24. Helgeson K, Stoneman P. Shoulder injuries in rugby players: Mechanisms, examination and rehabilitation. Phys Ther Sport 2014;15:218-27.

25. Herrington L, Horsley I, Whitaker L, et al. Does a tackling task effect shoulder joint position sense in rugby players? Phys Ther Sport 2008;9:67-71.

26. Hodgson Phillips L, Standen PJ, Batt ME. Effects of seasonal change in rugby league on the incidence of injury. Br J Sports Med 1998;32:144-8.

27. Hoskins W, Pllard H, Hough K, et al. Injury in rugby league. J Sci Med Sport 2006;9:46-56.

28. Ivey FM Jr, Calhoun JH, Rusche K, et al. Isokinetic testing of shoulder strength: normal values. Arch Phys Med Rehabil 1985;66:384-86.

29. Julienne R, Gauthier A, Moussay S, et al. Isokinetic and electromyographic study of internal and external rotator muscles of tennis player. Iso Exerc Sci 2007;15;173-82.

30. Malerba JL, Adam ML, Harris BA, et al. Reliability of dynamic and isometric testing of shoulder external and internal rotators. J Orthop Sports Phys Ther 1993;18:543-52.

31. McDonough A, Funk L. Can glenohumeral joint isokinetic strength and range of movement predict injury in professional rugby league. Phys Ther Sport 2014;15:91-96.

32. McDonough A, Funk L. Critical reflection of the advanced rehabilitation of an elite rugby league player sustaining a posterior Bankart lesion. Phys Ther Sport 2013;14:60-67.

33. Montgomery LC, Douglass LW, Deuster PA. Reliability of an isokinetic test of muscle strength and endurance. J Ortho Sports Ther 1989;15:315-22.

34. Morgan R, Herrington L. The effect of tackling on shoulder joint position sense in semiprofessional rugby players. Phys Ther Sport 2013;15:176-80.

35. Papalia R, Tecame A, Torre G, et al. Rugby and shoulder trauma: A systematic review. Transl Med UniSa 2015;12:5-13.

36. Saha AK. Dynamic stability of the glenohumeral joint. Acta Orthop Scand 1971;42:491-505.

37. Scoville AR, Arciero RA, Taylor DC, et al. End range eccentric antagonist/concentric agonist strength ratios: A new perepcetive in shoulder strength assessment. J Ortho Sports Phy Ther 1997;3:203-7.

38. Speranza M, Gabbett TJ, Greene D, et al. Changes in rugby league tackling ability during a competitive season: The relationship with strength and power qualities. J Strength Cond Res 2016;31:3311-318.

39. Stickley CD, Hetzler RK, Feemyer BG, et al. Isokinetic peak torque ratios and shoulder injury history in adolescent female volleyball athletes. $J$ Ath Train 2008;43:571-77.

40. van Cingel R, Kleinrensink G, Mulder P, et al. Isokinetic strength values, conventional ratio and dynamic control ratio of shoulder rotator muscles in elite badminton players. Iso Exerc Sci 


\section{Funding}

This research did not receive any specific grant from funding agencies in the public, commercial, or not-for-profit sectors

\section{$\underline{\text { Acknowledgment }}$}

Thanks to Dr John Stephenson for advice on statistical analyses. 